\title{
A NEW METHOD TO DETERMINE THE OPTICAL ORIENTATION OF BIAXIAL MINERALS: A MATHEMATICAL APPROACH
}

\author{
MICKEY E. GUNTER ${ }^{\S}$ \\ Department of Geological Sciences, University of Idaho, Moscow, Idaho 83844-3022, U.S.A. \\ BRENDAN TWAMLEY \\ University Research Office, University of Idaho, Moscow, Idaho 83844-3010, U.S.A.
}

\begin{abstract}
A mathematical approach has been developed to determine the optical orientation of biaxial minerals by combining spindle stage and X-ray-diffractometer measurements. First, a goniometer head, with crystal affixed, is screwed onto a spindle stage, and its orientation matrix for the biaxial indicatrix is determined. Next, the same goniometer head is transferred to a single-crystal Xray diffractometer, where the unit cell and, in turn, an orientation matrix for the reciprocal crystallographic axes are determined. The necessary transformations and calculations are then developed to relate these two orientation matrices mathematically. Examples for two orthorhombic minerals of known optical orientation, one monoclinic mineral of unknown optical orientation, and one triclinic mineral of known optical orientation are given. Several measurements were repeated to test the accuracy, reproducibility, and systematic errors of the method; these measurements yielded an accuracy and reproducibility of the method to within $1.0^{\circ}$. Once a suitable crystal has been selected and mounted on a goniometer head, all the required measurements and calculations can be performed in approximately one hour.
\end{abstract}

Keywords: optical orientation, spindle stage, X-ray diffraction, biaxial minerals.

\section{SOMMAIRE}

Nous avons développé une démarche mathématique pour déterminer l'orientation optique de minéraux biaxes, en combinant les mesures effectuées avec une platine à tige et un diffractomètre à rayons X. Tout d'abord, il s'agit de monter une tête goniométrique munie d'un cristal sur une platine à tige, et d'établir la matrice d'orientation de l'indicatrice biaxe. Ensuite, la même tête goniométrique est placée sur un diffractomètre à cristal unique, d'où il est possible de déterminer la maille élémentaire et, par la suite, une matrice d'orientation des axes cristallographiques dans l'espace réciproque. Les transformations et les calculs nécessaires sont ensuite développés pour établir mathématiquement le lien entre ces deux matrices d'orientation. Nous fournissons deux examples de minéraux orthorhombiques d'orientation optique connue, un exemple d'un minéral monoclinique dont l'orientation optique est inconnue, et un exemple d'un minéral triclinique dont l'orientation optique est connue. Plusieurs mesures ont été répétées afin d'évaluer la justesse, la précision, et les erreurs systématiques de la démarche. Ces mesures ont donné une justesse et une précision inférieure à $1.0^{\circ}$. Suite à la sélection et au montage d'un cristal approprié sur une tête goniométrique, toutes les mesures et tous les calculs nécessaires peuvent être effectués dans une heure environ.

(Traduit par la Rédaction)

Mots-clés: orientation optique, platine à tige, diffraction X, minéraux biaxes.

\section{INTRODUCTION}

The optical orientation of a mineral is an important physical property; among other uses in mineralogical research, it aids in mineral identification. However, it is difficult to determine and, in many cases, it is misdetermined. These factors, in addition to the senior author's work on determining the optical properties of the new mineral dickthomssenite (Hughes et al. 2001), prompted us to develop a new, simple mathematical method of determining the optical orientation of biaxial minerals. Determining the optical orientation of a mineral requires an integration of optical and X-ray-diffraction methods. The optical methods locate the direction of principal vibration $(\mathrm{X}, \mathrm{Y}, \mathrm{Z})$ and thus the orientation of the biaxial indicatrix. X-ray diffraction specifies the

$\S \quad$ E-mail address: mgunter@uidaho.edu 
axes $\left(a^{*}, b^{*}, c^{*}\right)$ in reciprocal crystallographic space, which are then used to locate the crystallographic axes $(a, b, c)$ in direct space. The direct crystallographic axes can also be located, although with less certainty and accuracy, on the basis of crystal morphology. We develop here the necessary transformations and calculations to relate these two orientation matrices mathematically. Furthermore, we provide examples of the application of our new method to orthorhombic, monoclinic and triclinic minerals. Table 1 provides a summary of the various symbols used in this paper.

\section{Rationale For the New Method}

The spindle stage (Fig. 1), as discussed in detail in Bloss (1981, 1999), provides a rapid and accurate method to obtain the orientation of the optical indicatrix of biaxial minerals. Once the orientation of the biaxial indicatrix has been determined, the principal vibration directions can be oriented into the plane of the stage of the microscope and made parallel to the lower polarizer of the microscope to determine all the indices of refrac- tion from the same crystal. Use of this method by Bloss and coworkers led to a series of optical studies summarized in the preface of Bloss (1999). The main goal in Bloss's work was to develop a simple method to orient single crystals to measure their indices of refraction; however, in the process he developed a method that mathematically represents the orientation of the biaxial indicatrix.

The basic premise in determining the orientation of the biaxial indicatrix with a spindle stage is that a mathematical relationship exists between the two optic axes and the extinction positions of a mineral as it is rotated on an axis parallel to the microscope stage. Given a set of extinction positions collected as the spindle axis is set to different values, a graphical method was developed to locate the principal vibrations directions (Bloss 1981). Next a computer program, EXCALIBR (Bloss 1981, Gunter et al. 1988, Bartelmehs et al. 1992), was developed to solve the extinction data numerically and provide the orientation of the biaxial indicatrix cast into the coordinate system of the microscope - spindle stage combination.
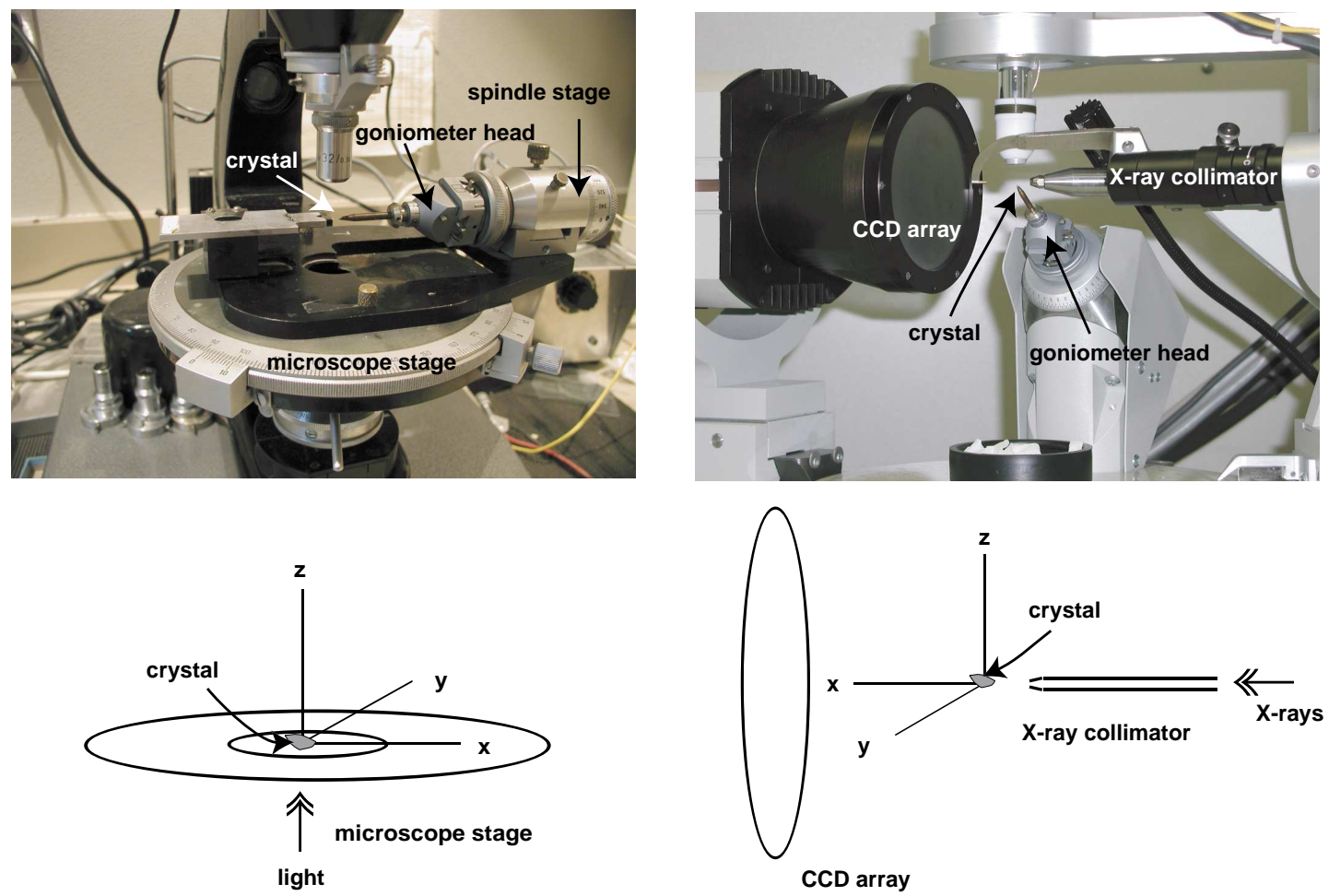

FIG. 1. Photographs of the microscope and spindle stage combination and the X-ray diffractometer with the goniometer head shown mounted on both; their associated coordinate systems also are shown. The goniometer head can easily be transferred from one to the other with a crystal affixed. Both systems use a Cartesian system of coordinates. For the spindle stage, light travels along the $z$ direction and the rotation axis coincides with $x$. In the diffractometer, X-rays travel along the $x$ axis. To convert the two systems, $z$ and $x$ of the spindle stage are transposed (see text for full discussion). 
Figure 1 shows a spindle stage attached to a microscope stage, and Figure 2 is a schematic view looking down on the microscope stage, with the spindle stage to the right. Also shown in Figure 2 is the system of stereographic projection developed in Bloss (1981) for use with the spindle stage. The spindle stage can rotate to different angles about an axis parallel to the microscope stage; these are called $\mathrm{S}$ angles and plot as great circles in Figure 2. For instance, a setting of $\mathrm{S}=40^{\circ}$ would rotate the plane tilted $40^{\circ}$ from the microscope stage into the plane of the stage. The $\mathrm{E}$ values are the angles a vector (e.g., a principal vibration direction) would make with the axis of rotation of the spindle stage. For instance, for $\mathrm{E}=20^{\circ}$, a vector would be inclined to the spindle axis by $20^{\circ}$. This vector would plot along the small circle in Figure 2. To fully describe the orientation of a vector, one must know its $\mathrm{S}$ and $\mathrm{E}$ polar coordinates. In Figure 2, a vector with $\mathrm{S}=40^{\circ}$ and $\mathrm{E}=20^{\circ}$ would plot at the intersection of these two planes. In essence, the $\mathrm{E}$ angles are the microscope stage settings. The extinction positions are really the $\mathrm{E}$ angles, and $\mathrm{E}$ values for extinction can be measured for any $S$ setting (i.e., there are extinction positions in any plane passing through an anisotropic mineral). These $\mathrm{S}$ and $\mathrm{E}$ values are the input for the EXCALIBR computer program. From these data, EXCALIBR will output the orientation of the biaxial indicatrix cast into the $\mathrm{S}$ and $\mathrm{E}$ coordinate system. Thus, to measure any principal index

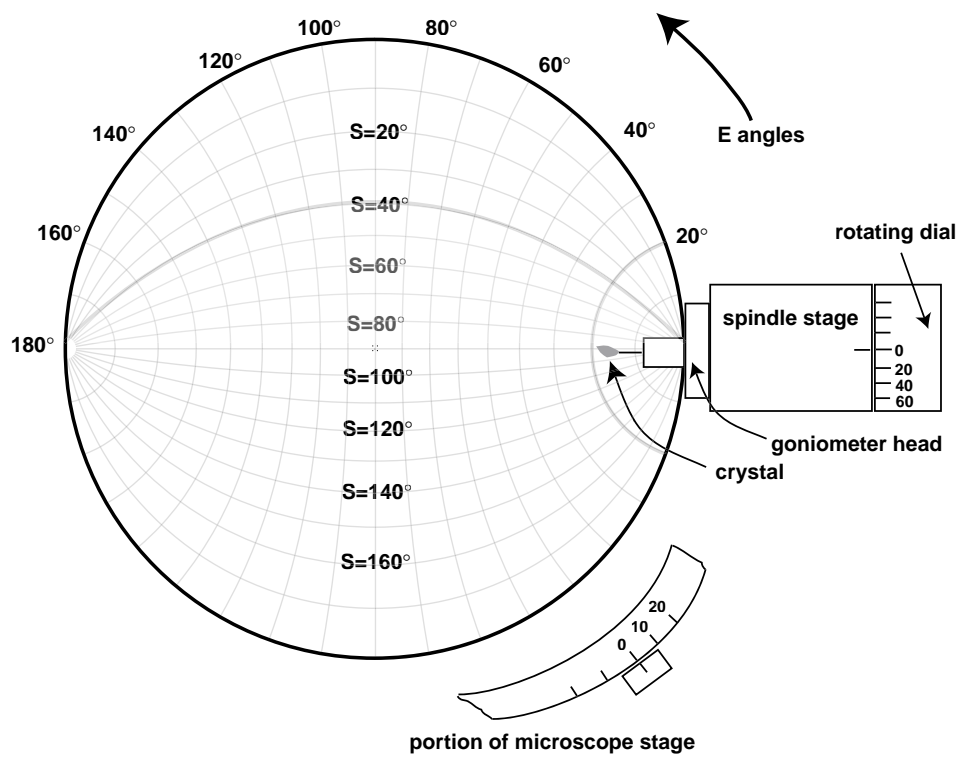

FIG. 2. The stereographic plotting developed by Bloss (1981) for use with the spindle stage, with a spindle stage and a portion of a microscope stage shown in their relative positions. (The crystal mounted on the spindle stage would actually be centered over the projection, but it is shifted to the right to aid in viewing the stereonet.) The $\mathrm{S}$ values represent settings on the spindle stage that would rotate a plane into the microscope stage. For instance, for an $\mathrm{S}$ setting of $40^{\circ}$, the great circle labeled $\mathrm{S}=40^{\circ}$ (shown with a bolder outline) would be rotated into the plane of the microscope stage. The E angles represent the angle between a vector (e.g., a principal vibration direction) and the spindle stage's axis of rotation. For instance, a direction parallel to the rotation axis of the spindle stage, the $x$ axis for the microscope - spindle stage combination in Figure 1, would have a $\mathrm{E}$ angle of $0^{\circ}$. Also, any vector plotting on a small circle would have the small circle value of $\mathrm{E}$ given in the above figure. For instance, a vector with $\mathrm{E}=20^{\circ}$ would plot somewhere on the small circle, which is shown in a bolder outline. Thus, the $\mathrm{E}$ angles represent the rotation of the microscope stage required to bring a vibration direction parallel to the microscope's lower polarizer so as to determine its index of refraction, and $\mathrm{S}$ is the rotation of the spindle stage required to bring the plane containing the vibration direction of interest into the plane of the microscope. In this example, a vector with $\mathrm{S}=40^{\circ}$ and $\mathrm{E}=20^{\circ}$, represented by the intersection of these two planes, would be placed in the plane of the microscope stage and made parallel to the E-W polarizer of a microscope by setting the spindle stage at $\mathrm{S}=40^{\circ}$ and the microscope stage at $\mathrm{E}=20^{\circ}$. 
of refraction for a mineral, the $\mathrm{S}$ setting will bring that direction into the plane of the microscope stage, and the $E$ angle will be the required rotation of the stage to orient the vibration parallel to the lower polarizer. [See Bloss (1981) for a more thorough discussion of the theory and use of the spindle stage. Bloss (1999) also provided an introduction to spindle stage use.]

Bloss (1981) dedicated an entire chapter to the optical orientation of minerals and the use of the spindle stage. Because a spindle stage uses an X-ray goniometer head, the same goniometer head, with crystal intact, can be easily transferred to various types of $\mathrm{X}$-ray-diffraction equipment; Figure 1 shows a goniometer head attached to the spindle stage and the same goniometer head attached to a single-crystal X-ray diffractometer. Bloss (1981) concentrated on the use of the precession camera to obtain information on optical orientation. First, optical data are collected and processed with the computer program EXCALIBR; the program will output the orientation of the biaxial indicatrix cast in the spindle-stage system of coordinates. Next, the goniometer head is transferred to a precession camera to locate the crystallographic vectors $\left(a^{*}, b^{*}, c^{*}\right)$ in reciprocal space. The main drawback of Bloss's method is that it is difficult to obtain the crystal orientation that would work on both the spindle stage and the precession camera. To obtain useful extinction data (i.e., that which can be solved by the algorithm in EXCALIBR) on the spindle stage, the principal directions of vibration must be inclined to the spindle axis by at least $10^{\circ}-20^{\circ}$. To orient a crystal for a precession photograph, a direct crystallographic axis must be made parallel to the X-ray beam. Often these two conditions are mutually exclusive for the arc rotations available on a goniometer head. Then the crystal must be removed and remounted and the entire process repeated. Roberts (1975) also presented a novel approach to determine the optical orientation of minerals by using a spindle stage that could be transferred from the microscope to an Xray diffractometer. However, his method also is very time-consuming, and one could take days to arrive at a single orientation. Both of these methods require angular measurements to be made on the X-ray film and be related back to the spindle-stage results, and both methods require alignment photographs, multiple X-ray photographs, and the use of X-ray or Polaroid film.

A single-crystal X-ray diffractometer can also be used to locate the reciprocal axes of a biaxial mineral. This information is contained in the orientation matrix obtained prior to any determination of a crystal structure. With older four-circle diffractometers, it would take approximately 3-4 hours to obtain an orientation matrix; this would save several days to locate the reciprocal axes when compared to the other X-ray camera methods. In addition, because the crystal requires no orientation set-up for single-crystal diffractometers, the goniometer head can be transferred to the diffractometer with no concern for remounting the crystal once the optical data have been obtained. Newer-generation CCD-based single-crystal diffractometers can obtain an orientation in less than 30 minutes. Our CCD system is shown in Figure 1. The other main advantage of this new method over older methods is that one obtains mathematical results for the orientation of the reciprocal axis. Given these values, a correlation can be made with the mathematical results obtained from EXACLIBR. Thus, optical orientations can be found mathematically and not by angular measurements made on X-ray film.

\section{BACKGROUND INFORMATION}

Gunter \& Bloss (1982) showed the optical orientation of andalusite, which changes from $\mathrm{Z}=a, \mathrm{Y}=b, \mathrm{X}$ $=c$ to $\mathrm{X}=a, \mathrm{Y}=b, \mathrm{Z}=c$ upon substitution of Mn and Fe for Al. This change makes the mineral appear optically isotropic, and likewise caused petrologists to overlook cases of andalusite within a certain $\mathrm{Mn}$ and $\mathrm{Fe}$ range of composition. After the oversight was pointed out, Grambling \& Williams (1985) found examples of such Mn- and Fe-enriched andalusite and used them to help reinterpret the aluminosilicate phase diagram.

Gunter \& Ribbe (1993) showed that the index of refraction along $c$ changes in the fibrous zeolites. The optical orientation changes from $\mathrm{X}=c$ in natrolite to $\mathrm{Y}$ $=c$ in mesolite to $\mathrm{Z} \approx c$ in scolecite; this finding provides a simple method (i.e., the sign of elongation) to distinguish these three minerals, which appear megascopically identical in hand specimen. A more detailed discussion of these and other examples is given in Gunter (1992). More recently, Palmer \& Gunter (2000) showed similar changes in samples of cation-exchanged heulandite, where $b$ coincided with either $\mathrm{X}, \mathrm{Y}$, or $\mathrm{Z}$ as mean index of refraction increases. In fact, Boles (1972) proposed the optical orientation as a method to distinguish clinoptilolite $(\mathrm{Y}=b)$ from heulandite $(\mathrm{Z}=b)$. Because heulandite undergoes changes in optical orientation as a function of changes in chemical composition (Gunter et al. 1994), Yang et al. (1997) used changes in extinction angles to measure diffusion boundaries and, in turn, to calculate diffusion coefficients for a series of cation-exchanged samples of heulandite. An understanding of optical orientation is critical in other disciplines than geology and mineralogy, such as non-linear optics, laser optics, or any scientific field that uses light transmission through biaxial materials.

Currently, the methods developed in this paper are being used to collect and interpret the polarized XANES spectra of a series of Fe-rich rock-forming minerals at the light source at Brookhaven National Laboratory. Beamline X26a was fitted with a spindle stage mounted on a rotating stage, so as to orient crystals with their principal directions of vibration parallel to the polarization direction of the high-intensity X-ray source. The first in a series of papers (Dyar et al. 2001) discussing this new technique was recently submitted. 


\section{Measurements with a Spindle Stage}

Use of the spindle stage, and its associated computer program EXCALIBR, greatly simplify obtaining the orientation of the optical indicatrix of a biaxial mineral. A single crystal is affixed to a glass fiber with fingernail polish and is then placed on a goniometer head. The goniometer head is screwed onto the spindle stage, which is mounted on the rotatable stage of a polarizing light microscope (Fig. 1). Next, the crystal is immersed in an index-matching fluid and a series of extinction positions are obtained. The microscope stage settings (i.e., values of $\mathrm{E}$ ) which cause the crystal to go extinct for $\mathrm{S}$ values of $0^{\circ}, 10^{\circ}, 20^{\circ} \ldots, 180^{\circ}$ are collected. These data are then submitted to EXCALIBR, which will provide the orientation of the $\mathrm{AB}, \mathrm{OB}$, and $\mathrm{ON}$ cast into the spindle system's coordinates.

Orientations of these vectors are given in a Cartesian coordinate set as well as polar coordinate system. Tables 2-5 provide sample output. The left sketch in Figure 1 shows the relationship of $\mathrm{x}, \mathrm{y}$, and $\mathrm{z}$ to the microscope stage. The rotation axis of the spindle stage (Fig. 1) is oriented parallel to $x$. The polar coordinate system $(\mathrm{S}, \mathrm{E})$ is mathematically related to the Cartesian set by:

$$
\begin{aligned}
& \mathrm{S}=\tan ^{-1} \mathrm{z} / \mathrm{y} \\
& \mathrm{E}=\cos ^{-1} \mathrm{x}
\end{aligned}
$$

As described above, the angle $\mathrm{S}$ is the rotation about the spindle stage's rotation axis that would bring a plane into the microscope stage; thus $\mathrm{S}=0^{\circ}$ is the microscope stage. The $\mathrm{E}$ angle is the angle a vector makes with the spindle axis (i.e., the $\mathrm{x}$ direction). E angles mark the extinction angle a vibration direction makes with $\mathrm{x}$.

EXCALIBR provides the orientations for $\mathrm{AB}, \mathrm{OB}$, and $\mathrm{ON}$, but to determine the optical orientation, the directions of $\mathrm{X}, \mathrm{Y}$, and $\mathrm{Z}$ must be found. In all cases, $\mathrm{Y}$ corresponds to ON. However, for optically positive minerals, $\mathrm{Z}$ corresponds to $\mathrm{AB}$, and $\mathrm{X}$ to $\mathrm{OB}$, and for optically negative minerals, $\mathrm{Z}$ corresponds to $\mathrm{OB}$, and $\mathrm{X}$ to $\mathrm{AB}$. To determine the relationships of $\mathrm{AB}$ and $\mathrm{OB}$ to $\mathrm{X}$ and $\mathrm{Z}$, the output from EXCALIBR is used to orient either $\mathrm{AB}$ or $\mathrm{OB}$ into the plane of the stage of the microscope and parallel to the lower polarizer. Next, a $45^{\circ}$ rotation is made and an accessory plate is used to determine whether $\mathrm{AB}$ or $\mathrm{OB}$ is $\gamma$. If, for instance, $\mathrm{AB}$ is $\gamma$, the crystal is optically positive, and $Z=\mathrm{AB}$ and $X$ $=\mathrm{OB}$; the reverse would be true if $\mathrm{AB}$ were $\alpha$ (i.e., $\mathrm{X}=$ $\mathrm{AB}$ and $\mathrm{Z}=\mathrm{OB}$ ). Tables $2-5$ list these relationships for a second set of matrices after they were determined on the minerals as described.

\section{Measurements with an X-Ray Diffractometer}

A single-crystal X-ray diffractometer (Fig. 1) provides a rapid method to obtain the orientation of the crystallographic axes of a mineral; this information is contained in the orientation matrix. The columns of the orientation matrix contain information about orientations, lengths, and interaxial angles of the reciprocal lattice vectors cast into the diffractometer coordinate system (Fig. 1). The first column contains information about $a^{*}$, the second about $b^{*}$, and the third about $c^{*}$. The rows are the $\mathrm{x}, \mathrm{y}$, and $\mathrm{z}$ components cast into the diffractometer coordinate system (Fig. 1), where the first row is the $\mathrm{x}$ component, the second is the y component, and third is the $\mathrm{z}$ component of a vector. (See the righthand columns in Tables 2-5 for examples of orientation matrices.)

The orientation matrix must be converted into a matrix that gives the directions of the reciprocal lattice vectors cast into unit vector form by removing the lengths and interaxial values; a unit vector is one in which the square root of the sum of its components equals unity. This conversion is required to compare the orientation of the crystallographic vectors to $\mathrm{X}, \mathrm{Y}$, and $\mathrm{Z}$. The conversion is made by multiplying each column of the orientation matrix by the correct combination of the cell parameters and interaxial angles. Column 1, which represents $a^{*}$, is multiplied by $a \sin \beta \sin \gamma$. Column 2 , which represents $b^{*}$, is multiplied by $b \sin \alpha \sin \gamma$. Column 3, which represents $c^{*}$, is multiplied by $c \sin \alpha \sin \beta$. The resulting matrix is given under "Normalized reciprocal axes vectors" in Tables $2-5$.

\section{Transformations of Coordinate Systems}

Comparing the two coordinate systems in Figure 1, it is clear that one system must be converted to match the other. By observation, light travels along the $\mathrm{z}$ direction in the microscope, but $\mathrm{X}$-rays travel along the $\mathrm{x}$ direction in the diffractometer. Thus, the $\mathrm{x}$ and $\mathrm{z}$ axes must be switched. It is easier to convert the coordinate system of the spindle stage to that of diffractometer system than the diffractometer's to that of the spindle stage; this is so because handedness is not a concern for X, Y, $\mathrm{Z}$ obtained with the spindle stage, whereas it is for the $a^{*}, b^{*}, c^{*}$ directions obtained on the diffractometer. Thus, all that is required is to switch the $x$ and $z$ components obtained by EXCALIBR for the X, Y, Z directions. These transformed values are given in Tables 2-5 under the heading "Transformed indicatrix vectors." If desired, the diffractometer's coordinate system can be converted to that of the spindle stage by switching the $x$ and $z$ components in the orientation matrix (i.e., interchanging rows one and three). However, the $b^{*}$ axes $\mathrm{x}$, $\mathrm{y}, \mathrm{z}$ values must be multiplied by -1 to correct the handedness in the reciprocal axis vector set.

Although not required to determine optical orientation mathematically (as explained later in the "Examples" section), it seems reasonable for visualization to use stereographic projections to view the relationships between $\mathrm{X}, \mathrm{Y}, \mathrm{Z}$ and $a^{*}, b^{*}, c^{*}$. This also provides a check on the calculations presented in the "Examples" 
section. Figure 2 shows the stereographic projection system used in the following examples. Figure 3 provides eight stereoplots and the formulas required to convert $x, y, z$ values into $S$ values. Depending on the signs of $\mathrm{x}, \mathrm{y}, \mathrm{z}$, the correct formula is chosen. These stereoplots show the $\mathrm{x}$ and $\mathrm{y}$ axes with $\mathrm{z}$ vertical. Solid dots plot on the upper hemisphere (i.e., $+\mathrm{z}$ values), whereas hollow dots plot on the lower hemisphere (i.e., $-\mathrm{Z}$ values). The single formula for calculating $\mathrm{S}$ (Eq. 1) works in EXCALIBR because the program always out-

\section{TABLE 1. OVERVIEW OF NOMENCLATURE USED IN THIS PAPER}

$\mathrm{X}, \mathrm{Y}, \mathrm{Z}$ : Three mutually perpendicular axes of the biaxial indicatrix, which correspond with the three principal indices of refraction $\alpha, \beta$, and $\gamma$, respectively.

$\mathrm{AB}, \mathrm{OB}, \mathrm{ON}$ : Abbreviations for the acute bisectrix, obtuse bisectrix, and optical normal, respectively. $O N$ coincides with $Y$, whereas $A B$ and $O B$ coincide with $X$ and $Z$ for optically negative minerals and with $Z$ and $X$ for optically positive minerals.

$a, b, c$ and $a^{*}, b^{*}, c^{*}$ : The crystallographic direct and reciprocal lattice vectors, respectively.

$\mathrm{x}, \mathrm{y}, \mathrm{z}$ : A set of Cartesian vectors for the spindle stage or diffractometer (Fig. 1).

S, E: A polar coordinate system used with the spindle stage (Fig. 2).

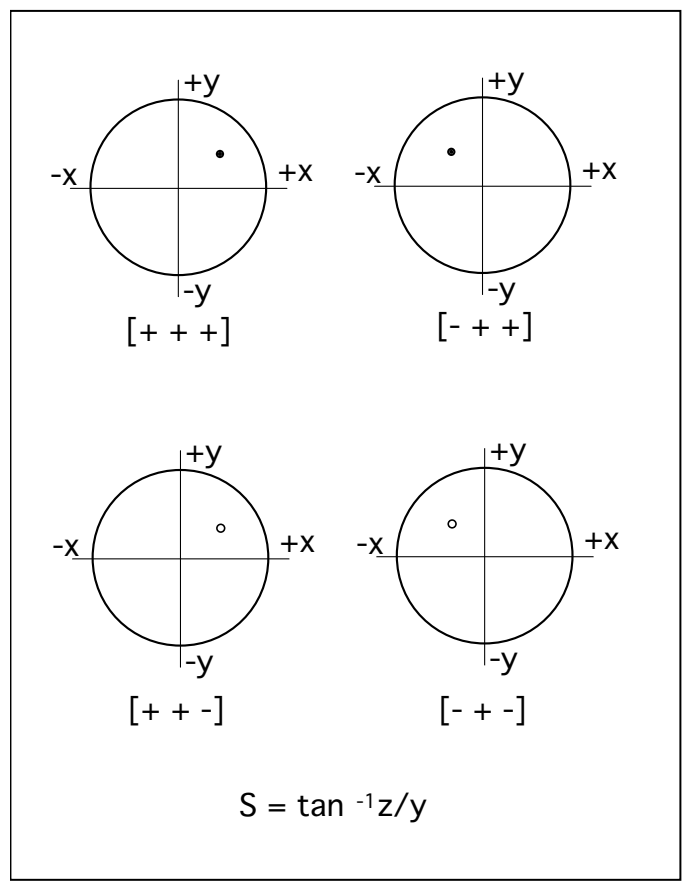

puts vectors with $+\mathrm{z}$ values. The three formulas in Figure 3 are required for two reasons: to maintain the handedness of the $a^{*}, b^{*}, c^{*}$ vectors and to correct for the $-\mathrm{z}$ values that arise in some cases for the optical directions that result from switching the $\mathrm{x}$ and $\mathrm{z}$ components of the spindle-stage system.

\section{EXAMPLES}

\section{Selection of a crystal}

The most difficult part of this procedure is selecting a single crystal suitable to obtain an orientation matrix and at the same time having it in a proper orientation to collect optical data. The problem is that a crystal must be in a "random" orientation to collect extinction datasets for EXCALIBR. Bloss (1981) described how to obtain such an orientation. Basically, one avoids mounting the crystal with $\mathrm{X}, \mathrm{Y}$, or $\mathrm{Z}$ near parallel to the spindle axis (the mathematical routines in EXCALIBR become unstable) or mounting the crystal with an optic axis nearly perpendicular to the spindle axis (this results in some $\mathrm{S}$ settings with no determinable extinction-position). It is not uncommon for a crystal to yield good optical data, have sharp extinction positions, and appear
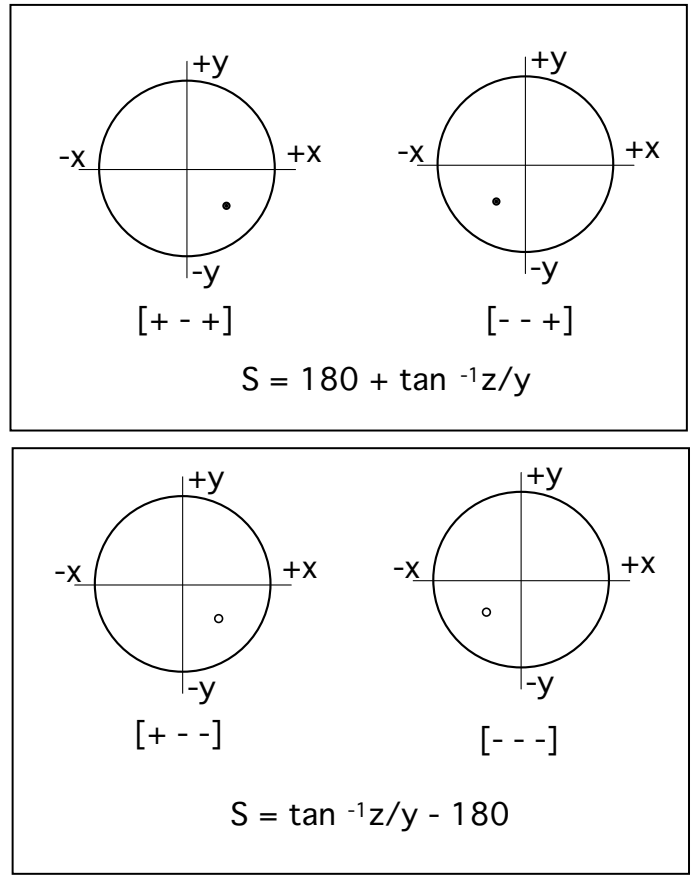

FIG. 3. Sign conventions for conversions from cartesian to polar coordinates. Stereoplots showing points (solid dots have $+z$ values and plot on the upper hemisphere, whereas hollow dots have $-\mathrm{z}$ values and plot on the lower hemisphere) plotted in each of the eight quadrants in Cartesian space. These are two-dimensional projections of the axes sets shown in Figure 1, projected down $+\mathrm{z}$. Three separate equations are required to calculate $\mathrm{S}$ as a function of the signs of [x y $\mathrm{z}]$. 
as a single crystal optically but turn out to be a twinned crystal or have some other problem that prevents the determination of a unit cell and its associated orientation matrix.

We worked around these problems by first making the measurements with the spindle stage, which requires about a half-hour, and then transferring the sample to the diffractometer to obtain an orientation matrix, a process that also requires about a half-hour. In a few cases, no unit cell could be found, and another crystal was selected. This process minimizes diffractometer operation, which is more costly to operate than the microscope. Also, if the diffractometer were used first, the crystal might not be in a proper orientation to obtain optical data.

\section{Orthorhombic case}

For orthorhombic minerals, the mutually perpendicular set of vectors $\mathrm{X}, \mathrm{Y}, \mathrm{Z}$ coincides with the mutually perpendicular set of vectors $a, b, c$ in one of six possible combinations. Also, because $a^{*}, b^{*}, c^{*}$ are mutually perpendicular sets of vectors, they coincide with $a, b, c$. A sample of andalusite (sample \#7, Gunter $\&$ Bloss 1982) with known optical orientation was selected to test the new method. First, an extinction dataset was collected and solved by EXCALIBR. The orientation of $\mathrm{AB}, \mathrm{OB}, \mathrm{ON}$ are given in Table 2 under "Indicatrix orientation from EXCALIBR." The vectors are written horizontally to mimic the output from EXCALIBR, which gives the $\mathrm{x}, \mathrm{y}, \mathrm{z}$ values for each direction. Next, by use of an accessory plate, as de-

TABLE 2. DERIVATION OF OPTICAL AND CRYSTALLOGRAPHIC ORIENTATION MATRICES FOR ANDALUSITE

\section{Indicatrix orientation from EXCALIBR Orientation matrix from diffractometer}

\begin{tabular}{crrc} 
& \multicolumn{1}{c}{$\mathrm{x}$} & \multicolumn{1}{c}{$\mathrm{y}$} & $\mathrm{z}$ \\
$\mathrm{AB}$ & 0.8111 & -0.1122 & 0.5740 \\
$\mathrm{OB}$ & -0.3783 & 0.6479 & 0.6612 \\
$\mathrm{ON}$ & -0.4461 & -0.7534 & 0.4830
\end{tabular}

\begin{tabular}{ccc}
$a^{*}=a$ & $b^{*}=b$ & \multicolumn{1}{c}{$c^{*}=c$} \\
& & \\
-0.0862 & 0.0595 & 0.1030 \\
-0.0810 & -0.0972 & -0.0200 \\
0.0497 & -0.0552 & 0.1460 \\
$a 7.7959$ & $b 7.8981$ & $c 5.5626$
\end{tabular}

Transformed indicatrix vectors

$\begin{array}{rrr}X=\mathrm{AB} & Y=\mathrm{ON} & Z=\mathrm{OB} \\ & & \\ 0.5740 & 0.4830 & 0.6612 \\ -0.1122 & -0.7534 & 0.6479 \\ 0.8111 & -0.4461 & -0.3783\end{array}$

Normalized reciprocal axis vectors $a^{*}=a \quad b^{*}=b \quad c^{*}=c$

$\begin{array}{rrr}-0.6720 & 0.4699 & 0.5729\end{array}$ $-0.6315$ $\begin{array}{lll}0.3875 & -0.4360 \quad 0.8121\end{array}$

$\mathrm{S}$ and $\mathrm{E}$ values for above vectors

\begin{tabular}{rrrrrrrr} 
& $\mathrm{X}$ & $\mathrm{Y}$ & $\mathrm{Z}$ & & $a^{*}=a$ & $b^{*}=b$ & $c^{*}=c$ \\
$\mathrm{~S}$ & $97.9^{\circ}$ & $-149.4^{\circ}$ & $-30.3^{\circ}$ & $\mathrm{S}$ & $148.5^{\circ}$ & $-150.4^{\circ}$ & $97.8^{\circ}$ \\
$\mathrm{E}$ & $55.0^{\circ}$ & $61.1^{\circ}$ & $48.6^{\circ}$ & $\mathrm{E}$ & $132.2^{\circ}$ & $62.0^{\circ}$ & $55.0^{\circ}$ \\
& \multicolumn{7}{c}{ Optical orientation: $\mathrm{X}=c, \mathrm{Y}=b, \mathrm{Z}=a$} \\
\hline
\end{tabular}

The cell parameters $a, b$ and $c$ are expressed in $\AA$. scribed above, we found that $X=A B$ and $Z=O B$, recalling that $\mathrm{Y}$ always coincides with $\mathrm{ON}$. Then the vectors for $\mathrm{AB}, \mathrm{OB}$, and $\mathrm{ON}$ were transposed and written in column form with the $\mathrm{x}$ and $\mathrm{z}$ components switched (Table 2 under "Transformed indicatrix vectors"). Lastly, to aid in visualization of the angular relationships of these vectors, the $\mathrm{S}$ and $\mathrm{E}$ values for $\mathrm{X}, \mathrm{Y}, \mathrm{Z}$ were calculated on the basis of Eq. 2, and the appropriate equation based on the signs of $\mathrm{x}, \mathrm{y}, \mathrm{z}$ given in Figure 3. The original and converted optical directions are given in the set of vectors on the left-hand side of Table 2 , whereas the data obtained and converted for the crystallographic directions obtained with the diffractometer are on the right-hand side of Table 2 for easier comparison.

The orientation matrix is given in the right column as the first entry, along with the values of the cell parameters. Next, this matrix is normalized into unit vectors. Lastly, the $\mathrm{S}$ and $\mathrm{E}$ values for $a^{*}, b^{*}, c^{*}$ are calculated. One can compare either the $\mathrm{S}$ and $\mathrm{E}$ values for $\mathrm{X}, \mathrm{Y}, \mathrm{Z}$ and $a^{*}, b^{*}, c^{*}$ or the matrices containing the unit vectors and, by observation, arrive at the optical orientation of $\mathrm{X}=c, \mathrm{Y}=b, \mathrm{Z}=a$. The $\mathrm{S}$ and $\mathrm{E}$ values for $\mathrm{X}, \mathrm{Y}, \mathrm{Z}$ and $a^{*}, b^{*}, c^{*}$ are plotted stereographically in Figure 4.

Another known orthorhombic sample was selected for a second test. This time, a sample of kanonaite, a Mn-dominant analogue of andalusite, was chosen. This sample, \#18 of Gunter \& Bloss (1982), has an optical orientation different from that of andalusite. Table 3 and Figure 5 show the results. Again, the left-hand side of the table contains the optical data, and the right-hand

TABLE 3. DERIVATION OF OPTICAL AND CRYSTALLOGRAPHIC ORIENTATION MATRICES FOR KANONAITE

Indicatrix orientation from EXCALIBR Orientation matrix from diffractometer

$\begin{array}{crccccr} & \mathrm{x} & \mathrm{y} & \mathrm{z} & a^{*}=a & b^{*}=b & c^{*}=c \\ & & & & & & \\ \mathrm{AB} & 0.1409 & -0.8970 & 0.4189 & 0.0826 & -0.0796 & -0.0761 \\ \text { OB } & -0.7531 & 0.1776 & 0.6334 & 0.0228 & -0.0523 & 0.1599 \\ \text { ON } & 0.6426 & 0.4047 & 0.6506 & -0.0944 & -0.0823 & -0.0280\end{array}$

Transformed indicatrix vectors

Normalized reciprocal axis vectors $\mathrm{X}=\mathrm{OB} \quad \mathrm{Y}=\mathrm{ON} \quad \mathrm{Z}=\mathrm{AB}$

$0.6334 \quad 0.6506 \quad 0.4189$

$\begin{array}{lll}0.1776 & 0.4047 & -0.8970\end{array}$

$\begin{array}{rrr}-0.7531 & 0.6426 & 0.1409\end{array}$

$a^{*}=a \quad b^{*}=b \quad c^{*}=c$

$0.5480 \quad-0.6326 \quad-0.4244$

$0.1789 \quad-0.4156 \quad 0.8918$

$\begin{array}{lll}-0.7405 & -0.6540 & -0.1562\end{array}$

$S$ and $E$ values for above vectors

$\begin{array}{rrrrrrrr} & \mathrm{X} & \mathrm{Y} & \mathrm{Z} & & a^{*}=a & b^{*}=b & c^{*}=c \\ \mathrm{~S} & -76.7^{\circ} & 57.8^{\circ} & 171.1^{\circ} & \mathrm{S} & -76.4^{\circ} & -122.4^{\circ} & -9.9^{\circ} \\ \mathrm{E} & 50.7^{\circ} & 49.4^{\circ} & 65.2^{\circ} & \mathrm{E} & 49.6^{\circ} & 129.2^{\circ} & 115.1^{\circ}\end{array}$

Optical orientation: $\mathrm{X}=a, \mathrm{Y}=b, \mathrm{Z}=c$

The cell parameters $a, b$ and $c$ are expressed in $\AA$ 


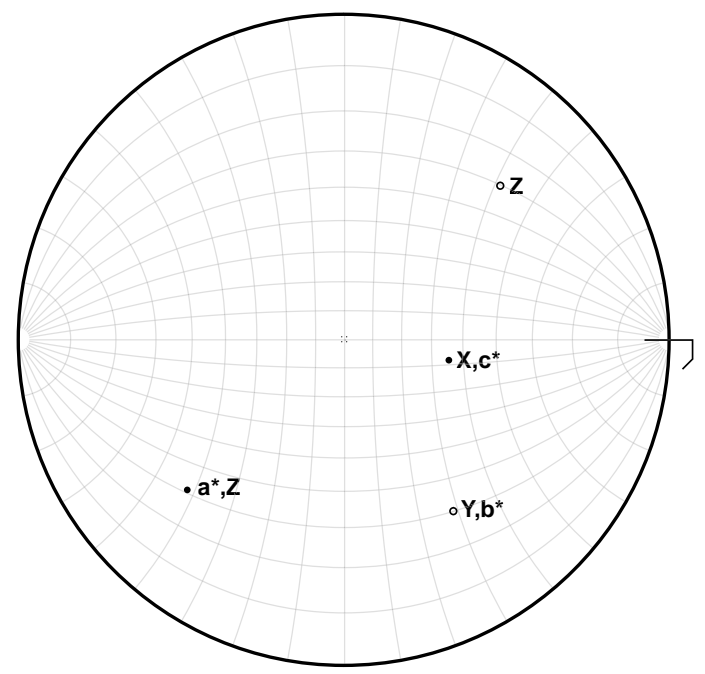

FIG. 4. Stereographic projection of the optical directions, X, $\mathrm{Y}, \mathrm{Z}$, and the reciprocal lattice vectors, $a^{*}, b^{*}, c^{*}$ (which coincide with $a, b, c$ for the orthorhombic case) based on the $\mathrm{S}$ and $\mathrm{E}$ values given in Table 2 for andalusite. The optical orientation is observed to be $\mathrm{X}=c, \mathrm{Y}=b$, and $\mathrm{Z}=$ $a$. Both ends of $\mathrm{Z}$ are plotted to show that $\mathrm{Z}=a$.

side shows the crystallographic data. For this sample, the optical orientation is $\mathrm{X}=a, \mathrm{Y}=b, \mathrm{Z}=c$. These two samples serve as a successful test of the method.

\section{Monoclinic case}

For monoclinic minerals, one of the three vectors $X$, $\mathrm{Y}$, or $\mathrm{Z}$ coincides with $b$. Thus, the optical orientation determines this relationship and then relates another optical direction to $c$. This is done in one of two ways: either by giving the angle between $c$ and the vibration direction that occurs in the obtuse angle $\beta$, or by stating the angle with $c$ and whether the vibration direction is in the obtuse or acute angle (i.e., between $c$ and $+a$, or between $c$ and $-a$, assuming $\beta$ is greater than $90^{\circ}$ ).

As stated above, the motivation to develop this method was provided by examination of a new mineral, dickthomssenite (Hughes et al. 2001). The required optical data were collected and are given in Table 4 in a format similar to that used with the other examples: optical data are presented in the left column, and crystallographic data are in the right column. By observation, it is clear that $\mathrm{Z}=b$; however, the normalized orientation-matrix only provides the directions of $a^{*}, b^{*}$, $c^{*}$; since $b^{*}$ coincides with $b, a$ and $c$ still must be found. There are two methods to locate $a$ and $c$ given $a^{*}, b^{*}$, $c^{*}$; they both rely on the fact that a direct crystallographic axis is perpendicular to a plane containing the

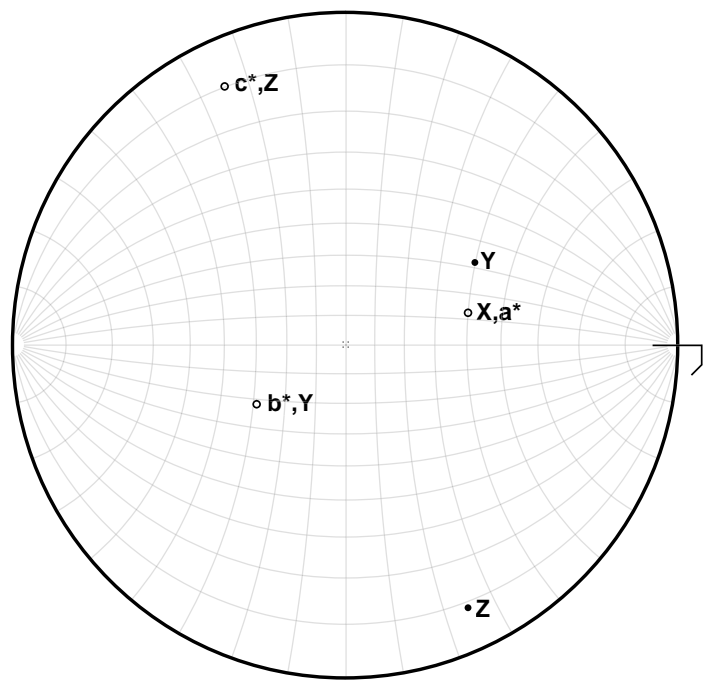

FIG. 5. Stereographic projection of the optical directions, X, $\mathrm{Y}, \mathrm{Z}$, and the reciprocal lattice vectors, $a^{*}, b^{*}, c^{*}$ (which coincide with $a, b, c$ for the orthorhombic case), based on the $\mathrm{S}$ and $\mathrm{E}$ values given in Table 3 for kanonaite. The optical orientation is observed to be $\mathrm{X}=a, \mathrm{Y}=b$, and $\mathrm{Z}=$ $c$. Both ends of $\mathrm{Y}$ and $\mathrm{Z}$ are plotted to show that $\mathrm{Y}=b$ and $\mathrm{Z}=c$.

TABLE 4. DERIVATION OF OPTICAL AND CRYSTALLOGRAPHIC ORIENTATION MATRICES FOR DICKTHOMSSENITE

\begin{tabular}{|c|c|c|c|c|c|c|}
\hline \multicolumn{4}{|c|}{ Indicatrix orientation from EXCALIBR } & \multicolumn{3}{|c|}{ Orientation matrix from diffractometer } \\
\hline & $\mathrm{x}$ & $\mathrm{y}$ & $\mathrm{z}$ & $a^{*}$ & $b^{*}=b$ & $c^{*}$ \\
\hline $\mathrm{AB}$ & -0.2522 & 0.8776 & 0.4076 & 0.0042 & 0.0551 & 0.0566 \\
\hline $\mathrm{OB}$ & 0.9146 & 0.0786 & 0.3966 & 0.0252 & 0.0093 & -0.0046 \\
\hline \multirow[t]{3}{*}{ ON } & -0.3161 & -0.4728 & 0.8225 & -0.0037 & 0.1269 & -0.0242 \\
\hline & & & & a 39.0656 & b 7.2107 & $c 16.3493$ \\
\hline & & & & \multicolumn{3}{|c|}{$\beta 97.584^{\circ}$} \\
\hline \multicolumn{4}{|c|}{ Transformed indicatrix vectors } & \multicolumn{3}{|c|}{ Normalized reciprocal axis vectors } \\
\hline & $\mathrm{X}=\mathrm{AB}$ & $\mathrm{Y}=\mathrm{ON}$ & $\mathrm{Z}=\mathrm{OB}$ & $a^{*}$ & $b^{*}=b$ & $c^{*}$ \\
\hline & 0.4076 & 0.8225 & 0.3966 & 0.1626 & 0.3973 & 0.9173 \\
\hline & 0.8776 & -0.4728 & 0.0786 & 0.9758 & 0.0671 & -0.0745 \\
\hline & -0.2522 & -0.3161 & 0.9146 & -0.1433 & 0.9150 & -0.3922 \\
\hline \multicolumn{4}{|c|}{$S$ and $E$ values for above vectors } & \multicolumn{3}{|c|}{$\mathrm{S}$ and $\mathrm{E}$ values for above vectors } \\
\hline & $\mathrm{X}$ & $\mathrm{Y}$ & $\mathrm{z}$ & $a^{*}$ & $b^{*}=b$ & $c^{*}$ \\
\hline $\mathbf{S}$ & $-16.0^{\circ}$ & $-146.2^{\circ}$ & $85.1^{\circ}$ & $-8.4^{\circ}$ & $85.8^{\circ}$ & $-100.7^{\circ}$ \\
\hline $\mathbf{E}$ & $65.9^{\circ}$ & $34.7^{\circ}$ & $66.6^{\circ}$ & $80.6^{\circ}$ & $66.6^{\circ}$ & $23.5^{\circ}$ \\
\hline \multicolumn{7}{|c|}{$57-0.37681 . Y \cdot$} \\
\hline
\end{tabular}

The cell parameters $a, b$ and $c$ are expressed in $\AA$ 
other two reciprocal axes (e.g., $a$ is perpendicular to the plane that contains $\left.b^{*} c^{*}\right)$.

Figure 6A shows a plot of $\mathrm{X}, \mathrm{Y}, \mathrm{Z}$ and $a^{*}, b^{*}, c^{*}$ based on their $\mathrm{S}$ and $\mathrm{E}$ values given in Table 4 . The direct axes $a$ and $c$ are plotted on the stereonet by finding the planes that are normal to $b^{*} c^{*}$ and $a^{*} b^{*}$, respectively, or the vectors that represent $a$ and $c$ are found by calculating the cross product of $b^{*} \times c^{*}$ and $a^{*} \times b^{*}$. The results of these calculations are given at the bottom of Table 4. Given vectors for $a$ and $c$, then, $\mathrm{Y} \bullet c$ (i.e., the dot product of the two vectors $)=\mathrm{Y}: c=16.5^{\circ}$ and $\mathrm{X} \cdot a=\mathrm{X}: a=24.0^{\circ}$. The stereographic projection (Fig. 6B) helps to show that Y:c is in the acute angle; this projection was made by rotating the crystallographic axes to the standard orientation to show optical orientation for monoclinic minerals (i.e., $c$ vertical and $b$ on the right). Also, note in Figure 6A that $a, a^{*}, c, c^{*}, \mathrm{X}$, and $\mathrm{Y}$ all lie on a great circle whose pole is $\mathrm{Z}=b=b^{*}$, and in Figure 6B, $a, c, \mathrm{X}$, and $\mathrm{Y}$ are all in the (010) plane and plot at $90^{\circ}$ to $b$.

\section{Triclinic case}

In the triclinic case, none of the optical directions $X$, $\mathrm{Y}, \mathrm{Z}$ coincides with $a, b, c$ except by chance. A sample of wollastonite was chosen as a test for triclinic minerals because of its known optical orientation: $\mathrm{Y}: b=4^{\circ}$ and X:c $=39^{\circ}$ (Deer et al. 1972). The direction for $a, b$, $c$ is calculated and given at the bottom of Table 5, and the optical orientation shown in Figure 7A. Whereas the observed $\mathrm{Y}: b$ value agrees closely with that in the literature, being off by only $1^{\circ}$, the value for $\mathrm{X}: c$ is off by $5^{\circ}$. In Figure $7 \mathrm{~B}$, the crystallographic axes have been rotated to the standard orientation to view the optical orientation for triclinic minerals (i.e., with $c$ vertical and $b$ near the right side of the projection). Interestingly, our $\mathrm{Z}: a$ value of $38.8^{\circ}$ agrees with the $\mathrm{X}: c$ literature value of $39^{\circ}$, possibly showing a mistake in the published values (e.g., in the earlier work, the $a$ and $c$ axes may have been switched). Regardless, the method clearly works for all biaxial minerals, and the time required to determine the optical orientation for an orthorhombic or triclinic mineral is the same: approximately one hour. Other methods may take several days, would be much more difficult to interpret, and require less precise measurements on X-ray photographs.

\section{ACCURACY, REPRODUCIBILITY, AND SYSTEMATIC ERRORS}

The results for the two orthorhombic minerals (Tables 2, 3) provide an easy check on the accuracy of the method, because the indicatrix vectors must coincide with the crystallographic axes. For instance, in andalusite, the direction of $\mathrm{X}$ and $c$ should be the same; the observed $\mathrm{S}$ values for $\mathrm{X}$ and $c$ differ by only $0.1^{\circ}$, whereas the $\mathrm{E}$ values are identical. The differences are a bit higher for the $\mathrm{Z}$ and $a$ directions, with an differ-
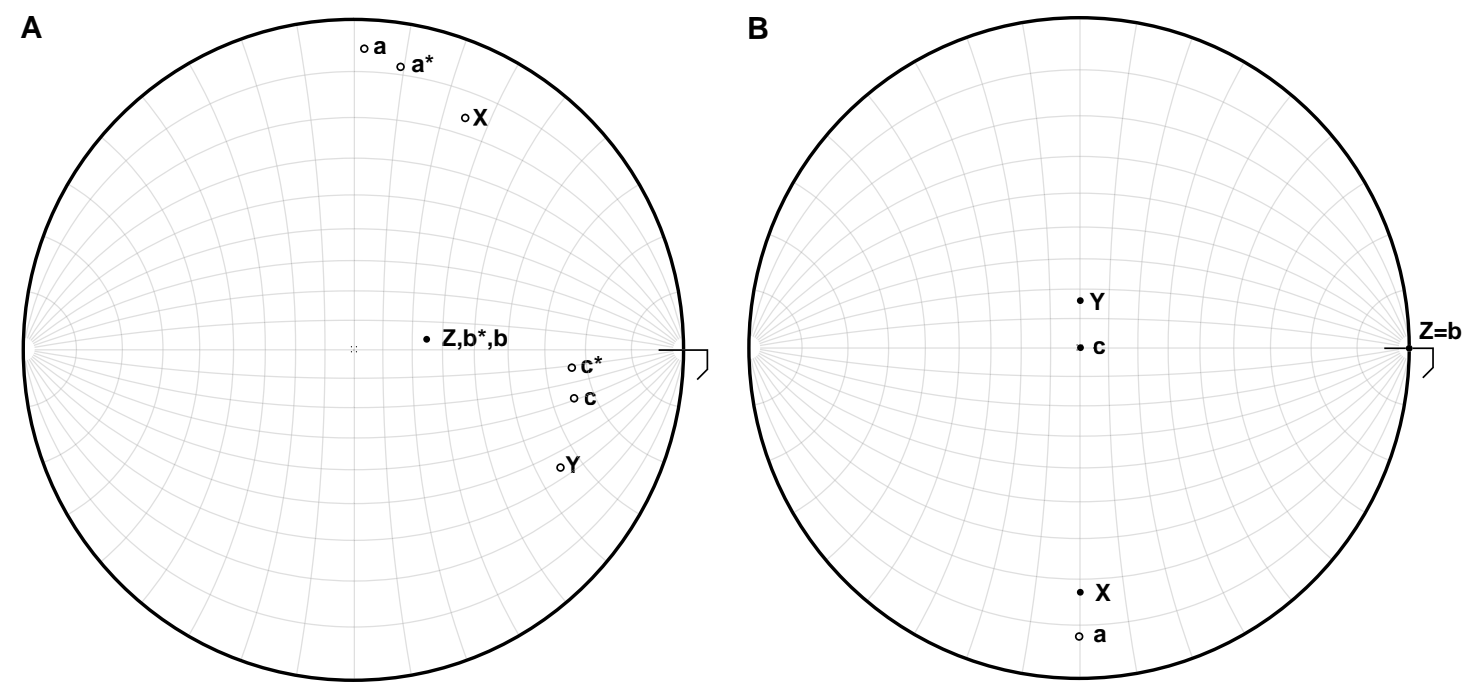

FIG. 6. A. Stereographic projection of the optical directions, X, Y, Z, and the reciprocal lattice vectors, $a^{*}, b^{*}, c^{*}$ (where $b^{*}$ and $b$ coincide for the monoclinic case), based on the $\mathrm{S}$ and $\mathrm{E}$ values given in Table 4 for dickthomssenite. To determine the optical orientation, $a$ and $c$ are also added to the projection (see text for details). Based on the projection, $\mathrm{Z}=b$ and X: $a=$ $16.5^{\circ}$. B. The direct crystallographic axes and X, Y, Z have been rotated to the standard position for monoclinic minerals, with $c$ vertical and $b$ on the right of the projection. After these are rotated, it is easier to view the optical orientation. 
TABLE 5. DERIVATION OF OPTICAL AND CRYSTALLOGRAPHIC ORIENTATION MATRICES FOR WOLLASTONITE

\begin{tabular}{|c|c|c|c|c|c|c|c|}
\hline \multicolumn{4}{|c|}{ Indicatrix orientation from EXCALIBR } & \multicolumn{4}{|c|}{ Orientation matrix from diffractomete } \\
\hline & $\mathbf{x}$ & y & z & & $a^{*}$ & $b^{*}$ & $c^{*}$ \\
\hline $\mathrm{AB}$ & 0.8537 & -0.0166 & 0.5204 & & -0.0215 & -0.1189 & 0.0726 \\
\hline OB & -0.0666 & 0.9878 & 0.1407 & & 0.1111 & 0.0482 & 0.0821 \\
\hline \multirow[t]{3}{*}{ ON } & -0.5164 & -0.1548 & 0.8422 & & -0.0646 & 0.0568 & 0.0905 \\
\hline & & & & & a 7.9246 & $b 7.3258$ & $c 7.0657$ \\
\hline & & & & & $\alpha 90.109$ & $\beta 95.136$ & $\gamma 103.375$ \\
\hline \multicolumn{4}{|c|}{ Transformed indicatrix vectors } & \multicolumn{4}{|c|}{ Normalized reciprocal axis vectors } \\
\hline & $\mathrm{X}=\mathrm{AB}$ & $\mathrm{Y}=\mathrm{ON}$ & $\mathrm{Z}=\mathrm{OB}$ & & $a^{*}$ & $b^{*}$ & $c^{*}$ \\
\hline & 0.5204 & 0.8422 & 0.1407 & & -0.1651 & -0.8474 & 0.5109 \\
\hline & -0.0166 & -0.1548 & 0.9878 & & 0.8531 & 0.3435 & 0.5778 \\
\hline & 0.8537 & -0.5164 & -0.0666 & & -0.4960 & 0.4048 & 0.6369 \\
\hline \multicolumn{4}{|c|}{$S$ and $E$ values for above vectors } & \multicolumn{4}{|c|}{$S$ and $E$ values for above vectors } \\
\hline & $x$ & $\mathbf{Y}$ & Z & & $a^{*}$ & $b^{*}$ & $c^{*}$ \\
\hline $\mathbf{S}$ & $91.1^{\circ}$ & $-106.7^{\circ}$ & $-3.9^{\circ}$ & $\mathbf{S}$ & $-30.2^{\circ}$ & $49.7^{\circ}$ & $47.8^{\circ}$ \\
\hline $\mathrm{E}$ & $58.6^{\circ}$ & $32.6^{\circ}$ & $81.9^{\circ}$ & $\mathrm{E}$ & $99.5^{\circ}$ & $147.9^{\circ}$ & $59.3^{\circ}$ \\
\hline \multicolumn{8}{|c|}{$\begin{array}{r}a^{*} \times b^{*}=c=\left[\begin{array}{lll}0.5157 & 0.4871 & 0.6662\end{array}\right], \mathrm{X} \cdot c=\mathrm{X}: c=34.0^{\circ} \\
a^{*} \times c^{*}=b=\left[\begin{array}{lll}-0.8299 & 0.1483 & 0.5312\end{array}\right], \mathrm{Y} \cdot b=\mathrm{Y}: b=5.0^{\circ} \\
b^{*} \times c^{*}=a=\left[\begin{array}{lll}-0.0151 & 0.7465 & -0.6651\end{array}\right], Z \cdot a=\mathrm{Z}: a=38.8^{\circ}\end{array}$} \\
\hline
\end{tabular}

The cell parameters $a, b$ and $c$ are expressed in $\AA$, and $\alpha, \beta$ and $\gamma$, in degrees.
TABLE 6. ERRORS IN REPRODUCIBILITY OF S AND E FOR ANDALUSITE BASED ON REPEATED SPINDLE STAGE AND DIFFRACTOMETER MEASUREMENTS

\begin{tabular}{|c|c|c|c|c|c|c|}
\hline \multicolumn{7}{|c|}{ Remeasurement: goniometer head left on } \\
\hline & \multicolumn{3}{|c|}{ spindle stage } & \multicolumn{3}{|c|}{ diffractometer } \\
\hline & $\mathrm{Z}=\boldsymbol{a}$ & $\mathrm{Y}=b$ & $\mathrm{X}=c$ & $a^{*}=a$ & $b^{*}=b$ & $c^{*}=c$ \\
\hline$\Delta \mathrm{S}$ & $-0.1^{\circ}$ & $-0.1^{\circ}$ & $-0.2^{\circ}$ & $0.0^{\circ}$ & $0.0^{\circ}$ & $0.4^{\circ}$ \\
\hline$\Delta \mathrm{E}$ & $0.1^{\circ}$ & $0.0^{\circ}$ & $0.0^{\circ}$ & $0.1^{\circ}$ & $0.3^{\circ}$ & $-0.1^{\circ}$ \\
\hline \multicolumn{7}{|c|}{ Remeasurement: goniometer head removed from } \\
\hline & \multicolumn{3}{|c|}{ spindle stage } & \multicolumn{3}{|c|}{ diffractometer } \\
\hline & $Z=a$ & $\mathrm{Y}=b$ & $\mathrm{X}=c$ & $a^{*}=a$ & $b^{*}=b$ & $c^{*}=c$ \\
\hline$\Delta \mathrm{S}$ & $0.5^{\circ}$ & $0.5^{\circ}$ & $0.1^{\circ}$ & $0.1^{\circ}$ & $-0.2^{\circ}$ & $-0.6^{\circ}$ \\
\hline$\Delta \mathrm{E}$ & $0.2^{\circ}$ & $-0.2^{\circ}$ & $-0.1^{\circ}$ & $0.3^{\circ}$ & $-1.1^{\circ}$ & $-0.6^{\circ}$ \\
\hline
\end{tabular}

ence in $\mathrm{S}$ of $1.2^{\circ}$ and $0.8^{\circ}$ for $\mathrm{E}$. The average and standard deviation for the twelve $\mathrm{S}$ and $\mathrm{E}$ pairs for andalusite and kanonaite are $0.6^{\circ}$ and $0.5^{\circ}$, respectively. Thus, the accuracy of the method is within $1^{\circ}$.

To assess reproducibility, the sample of andalusite was used. First, an extinction dataset was collected and solved by EXCALIBR. Then, without removing the goniometer head from the spindle stage, another dataset was collected and solved by EXCALIBR. Table 6 shows
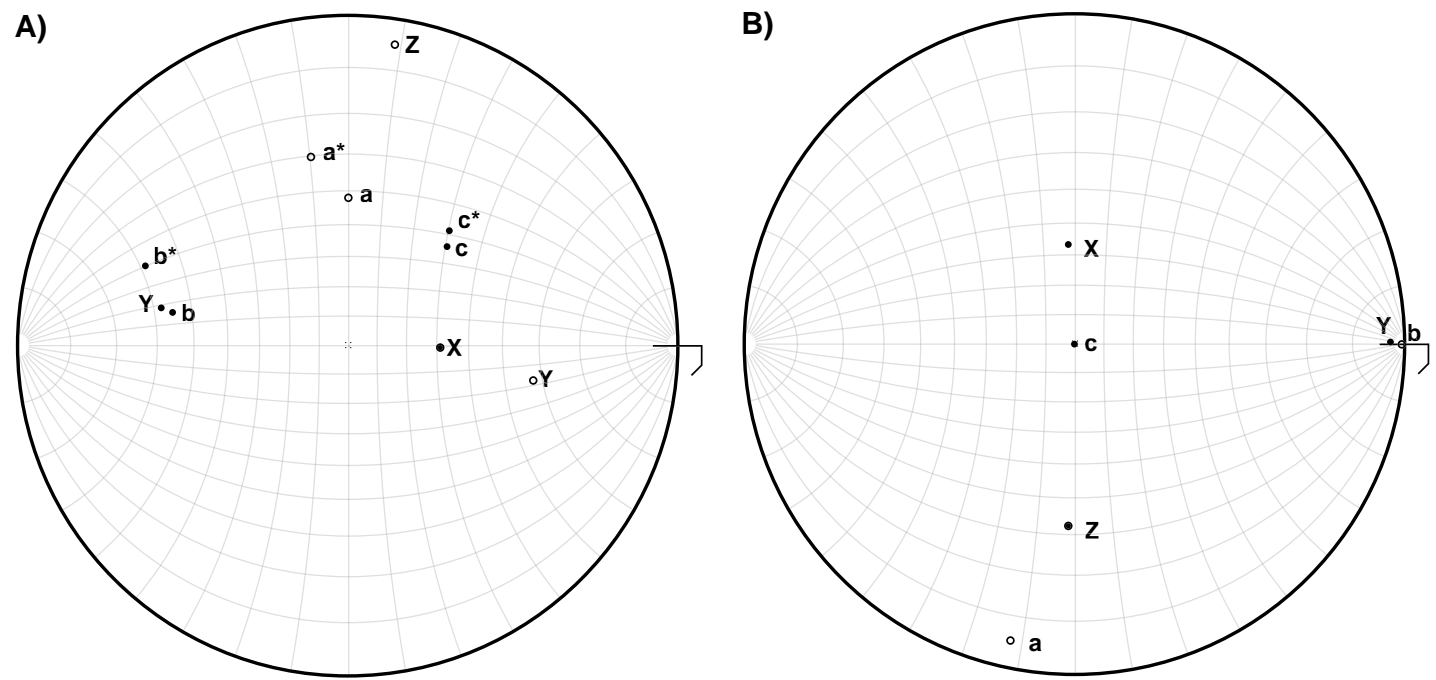

FIG. 7. A. Stereographic projection of the optical directions, X, Y, Z, and the reciprocal lattice vectors, $a^{*}, b^{*}, c^{*}$ (no reciprocal lattice vectors coincide with a direct vector in a triclinic case), based on the $\mathrm{S}$ and $\mathrm{E}$ values given in Table 5 for wollastonite. To determine the optical orientation, $a, b$, and $c$ are also added to the projection (see text for details). Then from the projection, or mathematically, $\mathrm{X}: c=34.0^{\circ}, \mathrm{Y}: b=5.0^{\circ}$, and Z: $a=38.8^{\circ}$. Both ends of $\mathrm{Y}$ are plotted to aid in visualization. B. The direct crystallographic axes and $\mathrm{X}, \mathrm{Y}, \mathrm{Z}$ have been rotated to the standard position for triclinic minerals, with $c$ vertical and $b$ plotting on the right side of the projection. After these rotations, it is easier to view the optical orientation. 
that the reproducibility is within $0.1^{\circ}$ to $0.2^{\circ}$. Next, the goniometer head was removed and then placed back on the spindle stage. This time the errors increased to as high as $0.5^{\circ}$ (Table 6). A similar set of experiments was performed on the diffractometer and showed similar errors in reproducibility (Table 6 ), with $1.1^{\circ}$ being the greatest error. Thus, the reproducibility of the data is similar to the accuracy, better than $1^{\circ}$.

One major systematic error can occur with this method. The S setting for the spindle stage must be set to read $270^{\circ}$ when the docking pin for the goniometer head is vertical at the 12 noon position. Stated another way, the lower arc (which is the arc farthest from the crystal) of a goniometer head should be parallel to the microscope stage. This can be done visually. To check for precise alignment, an orthorhombic crystal can be used as a test crystal. Because the crystal is orthorhombic, there should be an exact match (within the errors discussed above) between the $S$ values obtained from the spindle stage for the optical directions $\mathrm{X}, \mathrm{Y}, \mathrm{Z}$ and the $S$ values for the crystallographic directions obtained from the X-ray diffractometer; this was the case for the two orthorhombic samples above (Tables 2, 3). If the S values show a systematic error between the spindle stage and the diffractometer, the spindle axis S setting can be mechanically adjusted, by loosening the set screws and adjusting the rotating dial in Figure 2, or a correction applied to the input $S$ values. The newer version of EXCALIBR (Bartelmehs et al. 1992) will accept these corrected S values, whereas the older version of EXCALIBR (Gunter et al. 1988) required the S settings to be in $10^{\circ}$ increments.

\section{ACKNOWLEDGEMENTS}

Even though it has been a long time since he was their student, MEG thanks F.D. Bloss for teaching him all he knows about the spindle stage and G.V. Gibbs for teaching him all he knows about mathematical crystallography. The authors also thank Joe Mandarino, Bob Martin, and an anonymous reviewer for their helpful comments, which improved the manuscript.

\section{REFERENCES}

Bartelmehs, K.L., Bloss, F.D., Downs, R.T. \& BirCh, J.B. (1992): EXCALIBR II. Z. Kristallogr. 199, 185-196.

BLoss, F.D. (1981): The Spindle Stage: Principles and Practice. Cambridge University Press, Cambridge, U.K.

(1999): Optical Crystallography. Mineralogical Society of American, Washington, D.C., U.S.A.
Boles, J.R. (1972): Composition, optical properties, cell dimensions, and thermal stability of some heulandite group zeolites. Am. Mineral. 57, 1463-1493.

Deer, W.A., Howie, R.A. \& Zussman, J. (1972): RockForming Minerals. 2. Chain Silicates. Longman, Green and Co., London, U.K.

Dyar, M.D., Delaney, J.S., Gunter, M.E., Rossman, G.R. \& SutTON, S.R. (2002): Ferric iron in feldspar: calibration and interpretation of polarized XANES spectra. Am. Mineral. 87 (in press).

Grambling, J.A. \& WiLliams, M.L. (1985): The effects of $\mathrm{Fe}^{3+}$ and $\mathrm{Mn}^{3+}$ on aluminum silicate phase relations in northcentral New Mexico, U.S.A. J. Petrol. 26, 324-354.

GUNTER, M.E. (1992): Variation in optical class and optical orientation: the rule, not the exception. The Microscope 40, 81-93.

Armbruster, T., Kohler, T. \& Knowles, C.R. (1994): Crystal structure and optical properties of Na- and $\mathrm{Pb}$-exchanged heulandite-group zeolites. Am. Mineral. 79, 675-682.

\& BLoss, F.D. (1982): Andalusite-kanonaite series: lattice and optical parameters. Am. Mineral. 67, 1218-1228. revisited. Am. Mineral. 73, 1481-1482.

\& RiBBE, P.H. (1993): Natrolite group zeolites: correlations in optical properties and crystal chemistry. Zeolites 13, 435-440.

Hughes, J.M., Cureton, F., Marty, J., Gault, R., Gunter, M.E., Campana, C.F., Sommer, A., Rakovan, J. \& BRUESEKe, M.E. (2001): Dickthomssenite, $\mathrm{Mg}\left(\mathrm{V}_{2} \mathrm{O}_{6}\right) \bullet$ $7 \mathrm{H}_{2} \mathrm{O}$, a new mineral from the Firefly-Pigmay mine, Utah: descriptive mineralogy and atomic arrangement. Can. Mineral. 39, 1691-1700.

PAlmer, J.L. \& GunTer, M.E. (2000): Optical properties of natural and cation-exchanged heulandite group zeolites. Am. Mineral. 85, 225-230.

RoberTs, M.J.T. (1975): Indicatrix orientation for barium feldspars referred to crystallographic axes by computer using X-ray and extinction data. Am. Mineral. 60, 11131117.

Yang, Ping, Stolz, J., Armbruster, T. \& Gunter, M.E. (1997): $\mathrm{Na}, \mathrm{K}, \mathrm{Rb}$, and $\mathrm{Cs}$ exchange in heulandite single crystals: diffusion kinetics. Am. Mineral. 82, 517-525.

Received March 5, 2001, revised manuscript accepted September 5, 2001. 